\title{
Characteristics of crustal magnetic structures in the Tsushima (Ulleung) and Japan Basins from vector magnetic anomalies
}

\author{
Hiroyuki Kato ${ }^{1}$, Nobuhiro Isezaki ${ }^{2}$, Chan Hong Park ${ }^{3}$, Chang Hwan Kim ${ }^{3}$, and Masao Nakanishi ${ }^{1}$ \\ ${ }^{1}$ Graduate School of Science and Technology, Chiba University, 1-33, Yayoi-cho, Inage-ku, Chiba 263-8522, Japan \\ ${ }^{2}$ Faculty of Science, Chiba University, 1-33, Yayoi-cho, Inage-ku, Chiba 263-8522, Japan \\ ${ }^{3}$ Marine Environment Research Department, Korea Ocean Research and Development Institute, Ansan, 425-600, Korea
}

(Received November 1, 2006; Revised May 28, 2007; Accepted May 30, 2007; Online published July 20, 2007)

\begin{abstract}
Magnetic surveys by a Deep-tow Three-Component Magnetometer (DTCM) were conducted in the northeastern part of the Japan Basin and the central part of the Tsushima (Ulleung) Basin. Magnetic lineations are recognized clearly in the former area, whereas they were not recognized by previous studies in the latter area. The high-quality vector magnetic anomaly data obtained by DTCM enables the precise determination of the strikes of magnetic lineations and the positions of magnetic boundaries. Magnetic anomalies measured by DTCM show the characteristics of linear magnetic anomalies in both basins. The strikes of magnetic lineations are $\mathrm{N} 47^{\circ} \mathrm{E}$ in the Japan Basin and $\mathrm{N} 82^{\circ} \mathrm{E}$ in the Tsushima Basin. The estimated magnetization intensities of magnetic source models constructed from the amplitudes of analytic signal calculated from vector anomalies and the crustal structures determined by seismic studies are similar to those of typical extrusive basalt in both basins. The observed anomalies in the Japan Basin contain a short wavelength anomaly which cannot be explained by the model. Their ages may be chrons C5Cr (16.726-17.277 Ma), C5Dn (17.277-17.615 Ma), C5Dr (17.615-18.281 Ma), and subchron C5Dr.1n which was identified by a paleomagnetic study. The estimated half-spreading rate is $2.0 \mathrm{~cm} / \mathrm{yr}$, which is slower than that estimated by previous study. The observed anomalies in the Tsushima Basin show that there is a partial magnetization high. This may indicate that not all of the sources of magnetic lineations in the Tsushima Basin changed to low magnetization by the effect of thick sediment cover and the intrusions of a large amount of dikes after the formation.
\end{abstract}

Key words: Crustal magnetic structure, vector magnetic anomaly, Tsushima Basin, Japan Basin, Japan Sea.

\section{Introduction}

The Japan Sea (East Sea) is one of the back-arc basins in the northwestern Pacific and comprises three main basins, the Japan, Yamato, and Tsushima (Ulleung) Basins (Fig. 1). It is important for any understanding of the formation process of the Japan Sea to reveal the features of the crustal structures of their basins. Previous studies based on seismic methods showed that the crust of the eastern part of the Japan Basin has the features of a typical oceanic crust (Hirata et al., 1992), whereas the crusts of the Yamato and Tsushima Basins are thicker (Hirata et al., 1989; Shinohara et al., 1992; Kim et al., 1994; Kurashimo et al., 1996; Kim et al., 1998; Lee et al., 1999; Nishizawa and Asada, 1999; Kim et al., 2003; Cho et al., 2004; Sato et al., 2006a, b).

The existence of marine magnetic anomaly lineations indicates that the basin was formed by seafloor spreading; that is, the crustal structure is of oceanic type. Isezaki (1986a) suggested that there are magnetic lineations between chron $6 \mathrm{~A}$ and chron $5 \mathrm{~A}$ and that the half-spreading rate is $3.4 \mathrm{~cm} / \mathrm{yr}$ in the northeastern part of the Japan Basin based on data obtained using a proton precession magnetometer (PPM) and a shipboard three-component magne-

Copyright (c) The Society of Geomagnetism and Earth, Planetary and Space Sciences (SGEPSS); The Seismological Society of Japan; The Volcanological Society of Japan; The Geodetic Society of Japan; The Japanese Society for Planetary Sciences; TERRAPUB tometer (STCM). The studies based on PPM observations suggested that there are magnetic lineations between chron 7A and chron 5E in the eastern part of the Japan Basin and that the strikes are $\mathrm{N} 70^{\circ} \mathrm{E}$ and the half-spreading rate is 3.0 cm/yr (Tamaki and Kobayashi, 1988; Tamaki, Pisciotto, Allan et al., 1990). Based on STCM data, Seama and Isezaki (1990) suggested that the strikes of magnetic lineations in the north region of the eastern part of the Japan Basin are $\mathrm{N} 40^{\circ} \mathrm{E}$ and those in the south region are $\mathrm{N} 60^{\circ} \mathrm{E}$. Thus, the studies based on magnetic methods support the conclusion that the crust of the eastern part of the Japan Basin was formed by seafloor spreading, although the strikes of magnetic lineations determined by PPM and STCM are different.

In the Yamato and Tsushima Basins, however, magnetic lineations have not been found because of low amplitudes and a complex distribution of magnetic anomalies (Isezaki, 1986a). Kono (1986) suggested that the contamination by off-ridge volcanism makes the identification of magnetic lineations difficult in the Japan Sea. Tamaki et al. (1992) proposed that there are no magnetic lineations in the Yamato and Tsushima Basins because they formed by continental crust thinning and extension. Isezaki and Shevaldin (1996) pointed out that there are no magnetic lineations in the Yamato Basin, only spotted magnetic anomalies associated with the Yamato Seamount Chain. Fukuma et al. (1998) suggested that sill-sediment complexes are respon- 


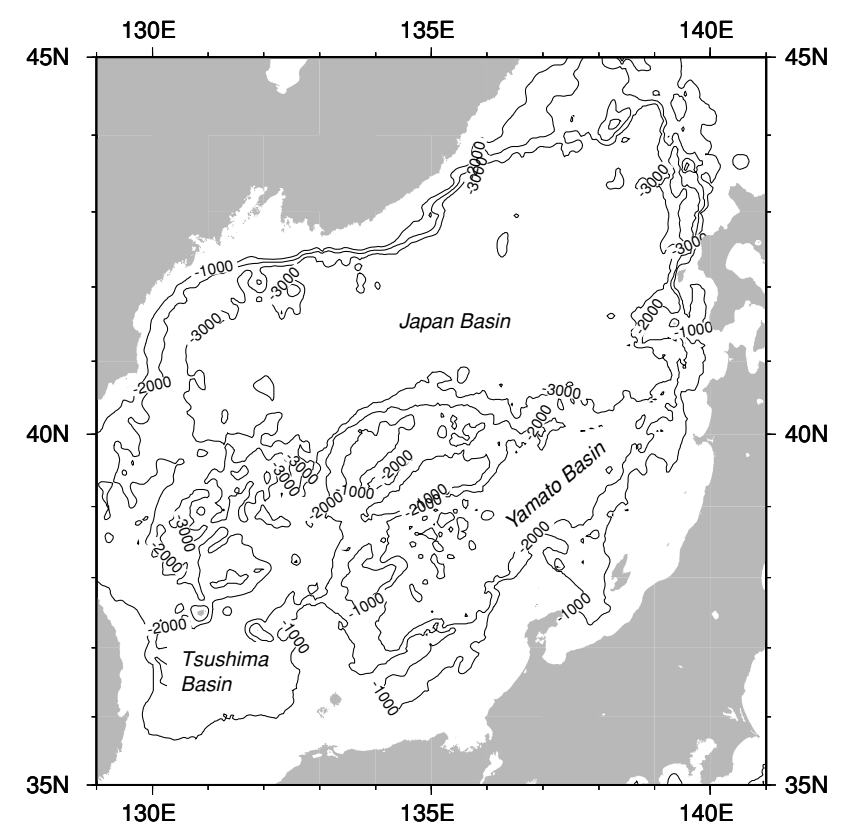

Fig. 1. Bathymetry of the Japan Sea. Bathymetric contour interval is $1000 \mathrm{~m}$. In this paper, the Tsushima and Japan Basins are defined as the areas encircled by the $1000 \mathrm{~m}$ and $3000 \mathrm{~m}$ sea depth contour lines.

sible for the absence of magnetic lineations in the Yamato Basin, while Park (1998) suggested that the spreadingrelated magnetic anomalies in the Tsushima Basin are degraded by volcanic sills and flows or dikes intercalated into sediment overlying basement. Kim et al. (1998) argued that the source of magnetic lineation disappeared due to the effect of thick sediment cover. Thus, the characteristics and origins of magnetic anomalies are still unclear, and the formation mechanisms of the Yamato and Tsushima Basins have not yet been determined.

Measurement of the three components of the geomagnetic field provides more information about the origin of magnetic anomaly than that of total intensity because the anomaly is a vector field. The observations of the vector magnetic anomaly onboard a ship have been conducted since 1980s, and methods of measurement and data analysis have been developed (e.g., Isezaki, 1986b; Seama et al., 1993; Korenaga, 1995). For the Japan Sea, where there are complex magnetic anomalies, the magnetic survey by a three-component magnetometer should be effective. An additional challenge to analyzing magnetic anomalies in the Japan Sea is that their amplitudes are small, almost between $-100 \mathrm{nT}$ and $100 \mathrm{nT}$ on the sea-surface (Isezaki and Shevaldin, 1996). Hence, deep-tow observation is required to describe the magnetic anomalies in the Japan Sea more in detail and accurately.

To acquire the three components and large amplitudes of magnetic anomaly, a Deep-tow Three-Component Magnetometer (DTCM) was developed in 1994. In 1998, a magnetic survey by DTCM was conducted in the East Pacific Rise (Yamamoto et al., 2005). DTCM can acquire highquality vector magnetic anomaly data than STCM because DTCM is not affected by the noise due to a ship body. In 2004 and 2005, magnetic surveys by DTCM were conducted in the central part of the Tsushima Basin where mag-
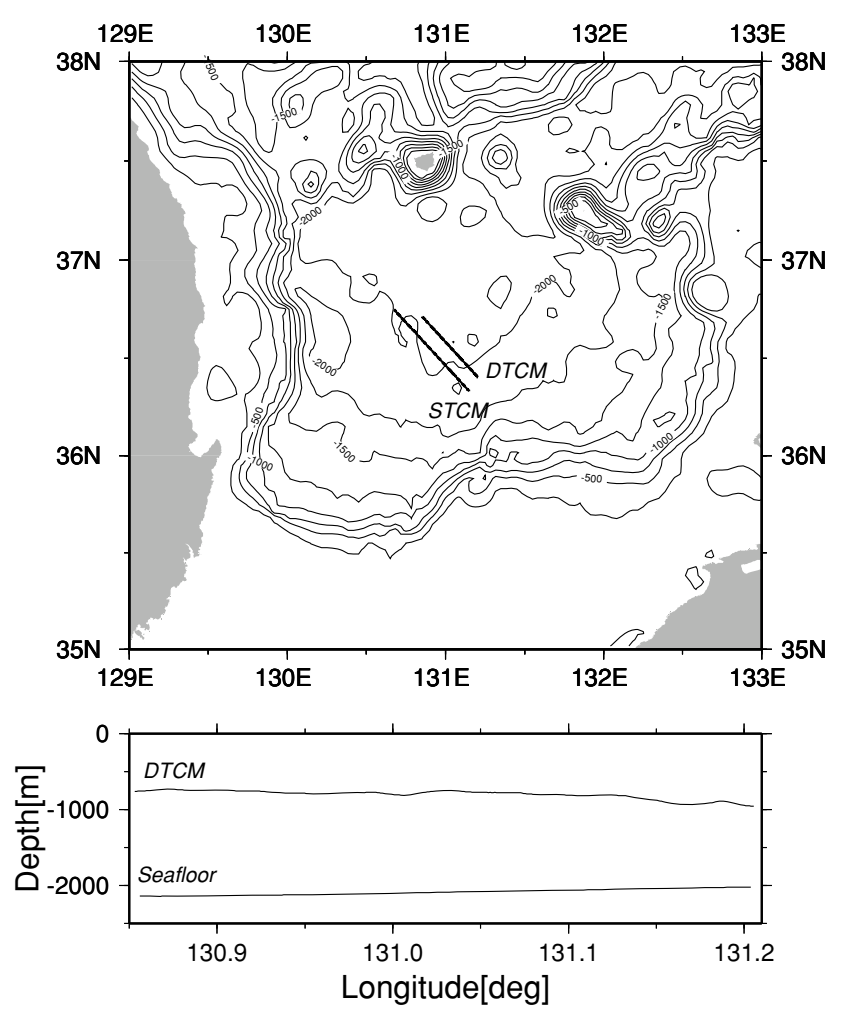

Fig. 2. Locations of DTCM and STCM profiles in the Tsushima Basin. (Top) Bathymetry. (Bottom) Depth of DTCM. Bathymetric contour interval is $250 \mathrm{~m}$.

netic lineations are not recognized and in the northeastern part of the Japan Basin where they are clearly recognized. The main object of this study is to reveal the characteristics of the magnetic anomalies and their sources in both basins by taking advantage of vector anomalies.

\section{Observation}

DTCM has two main parts, one is a three-axes fluxgate sensor which measures three components of the magnetic field with an accuracy of $1 \mathrm{nT}$, and the other is a Ring Laser Gyro (RLG) which can measure roll, pitch, and yaw with resolution of $0.005^{\circ}$ and determine latitude and longitude by the method of inertial navigation. DTCM is equipped with a pressure gauge which measures the depth of DTCM with a resolution of $0.2 \mathrm{~m}$ and a $10 \mathrm{kHz}$ down-looking echo sounder which measures the altitude of DTCM above the seafloor. Using an acoustic transducer (12-14 kHz bandwidth) attached on a surfboard towed behind a ship, communication is possible between the DTCM and a laboratory on board. In addition, DTCM can be used as a STCM by placing the DTCM on the deck.

In August 2004 and April 2005, we conducted magnetic surveys by DTCM, STCM, and PPM in the Tsushima and Japan Basins. In the Tsushima Basin, the magnetic survey was conducted by the R/V Eardo of Korea Ocean Research and Development Institute (KORDI), and we acquired one DTCM track line and one STCM track line (Fig. 2). The DTCM was towed at a depth of $807 \pm 60 \mathrm{~m}$, which is about $1200 \mathrm{~m}$ above seafloor, which is almost flat. In the Japan Basin, the magnetic survey was conducted during the KT05-8 research cruise by R/V Tansei-maru of Japan 

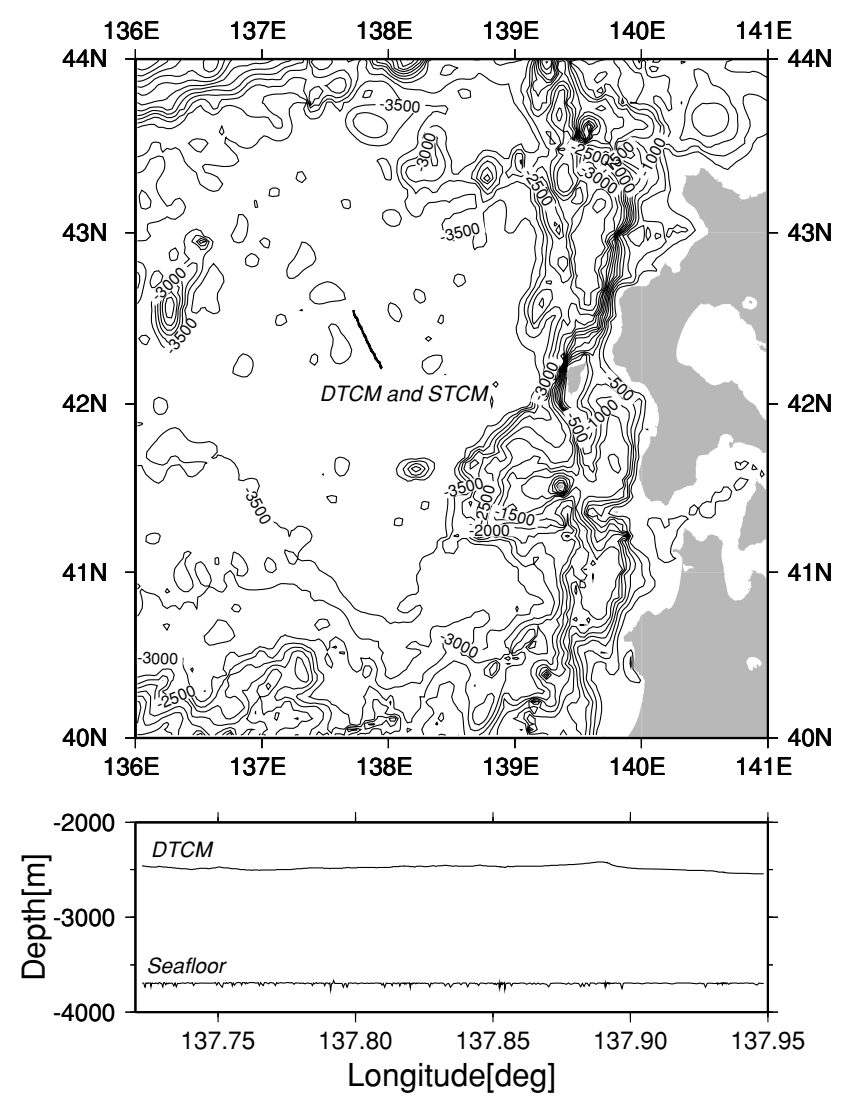

Fig. 3. Locations of DTCM and STCM profiles in the Japan Basin. (Top) Bathymetry. (Bottom) Depth of DTCM. Bathymetric contour interval is $250 \mathrm{~m}$.

Agency for Marine-Earth Science and Technology (JAMSTEC). We acquired one DTCM track line and one STCM track line (Fig. 3). The STCM survey in the Japan Basin was conducted above the DTCM track line. The DTCM was towed at a depth of $2480 \pm 26 \mathrm{~m}$, about $1200 \mathrm{~m}$ above the seafloor, which is almost flat. In both surveys, the communication system of DTCM did not operate well. In addition, transducer and RLG troubles occurred during the observations in the Tsushima and Japan Basins. We therefore were not able to conduct deeper and longer observations.

\section{The Characteristics of Magnetic Anomaly}

The three components of the magnetic field measured by the fluxgate sensor depend on the direction of the sensor. We converted observed magnetic fields to northward $(X)$, eastward $(Y)$, and vertical downward $(Z)$ components using the roll, pitch, and yaw angles measured by RLG, and calculated total intensity $(T)$ directly from the observed three components of the magnetic field. The converted three components of the magnetic fields and total intensity were reduced to magnetic anomalies by subtracting IGRF10 (IAGA, 2005). The calibration of STCM data for the removal of noise caused by ship's magnetization was carried out according to the method of Isezaki (1986b).

One of the expected characteristics of the structure generated by seafloor spreading is two-dimensionality. To evaluate whether the observed anomalies are generated by 2-D magnetic structure, we adopted the method suggested by
Isezaki (1986b). This method is based on the characteristics of a magnetic field generated by 2-D magnetic structure: the amplitude of the horizontal component parallel to the strike is zero, and the horizontal component normal to the strike and the vertical component have a constant phase difference of $\pi / 2$ (Blakely et al., 1973; Isezaki, 1986b; Parker and O'Brien, 1997). We first converted $X$ and $Y$ components to two horizontal components (named $H 1$ and $H 2$ ) by minimizing root mean square (RMS) of $\mathrm{H} 2$.

$$
\left(\begin{array}{l}
H 1 \\
H 2
\end{array}\right)=\left(\begin{array}{rr}
\cos \left(90^{\circ}-A\right) & -\sin \left(90^{\circ}-A\right) \\
\sin \left(90^{\circ}-A\right) & \cos \left(90^{\circ}-A\right)
\end{array}\right)\left(\begin{array}{l}
X \\
Y
\end{array}\right)
$$

where $A$ is the azimuth which minimizes RMS of $H 2$ and defined between $\mathrm{N} 90^{\circ} \mathrm{W}$ and $\mathrm{N} 90^{\circ} \mathrm{E}$ measured from geographical north. $H 1$ is defined as the component anticlockwise perpendicular to $H 2$. We then compared $H 1$ to $Z$ with the pahse shifted by $\pi / 2$.

In general, band-pass filtering is required for the analysis of STCM data because the anomalies measured by STCM contain the noises caused by a ship's body and other sources (e.g., Korenaga, 1995). The anomalies measured by DTCM also contain noises because it is composed of a lot of electronic equipment. In this study, we utilized a band-pass filter with the continuous wavelet transform (Torrence and Compo, 1998) to extract the anomalies due to a 2-D magnetic source for both STCM and DTCM data. We first decomposed the observed anomalies into those of each scale with the Morlet wavelet and then extracted the anomalies which have the smallest RMS of $H 2$ (or the largest RMS of $H 1$ ) and the high correlation coefficient of $H 1$ and $Z$ with the phase shifted by $\pi / 2$.

The unfiltered anomalies obtained by STCM and DTCM in the Tsushima Basin show the azimuths $\mathrm{N} 32^{\circ} \mathrm{E}$ and $\mathrm{N} 86^{\circ} \mathrm{E}$ which minimize the RMSs of $\mathrm{H} 2$ (Figs. 4 and 5). The RMSs of $H 2$ of the unfiltered STCM and DTCM data are $43.3 \mathrm{nT}$ and $25.6 \mathrm{nT}$, respectively. The correlation coefficients between $H 1$ and phase-shifted $Z$ of the unfiltered STCM and DTCM data are 0.18 and 0.88 , respectively. We extracted the anomalies of the scales corresponding to the Fourier wavelength $18.64-37.29 \mathrm{~km}$ and $11.48-60.58 \mathrm{~km}$ from the STCM and DTCM data by the band-pass filtering. The filtered STCM and DTCM anomalies show the azimuths $\mathrm{N} 77^{\circ} \mathrm{E}$ and $\mathrm{N} 82^{\circ} \mathrm{E}$ which minimize the RMSs of $\mathrm{H} 2$ (Figs. 4 and 5). The RMSs of $H 2$ of the filtered STCM and DTCM data are $14.3 \mathrm{nT}$ and $17.3 \mathrm{nT}$, respectively. The correlation coefficients between $H 1$ and phase-shifted $Z$ of the filtered STCM and DTCM data have the same value, 0.96. The PPM $T$ has the high correlation to the filtered STCM $T$, but the amplitude is higher than that of the filtered DTCM $T$ (Fig. 5), probably because the band-pass filter removed the long wavelength components of DTCM anomalies too well.

The unfiltered anomalies obtained by STCM and DTCM in the Japan Basin show the same azimuth $\mathrm{N} 47^{\circ} \mathrm{E}$ which minimizes the RMSs of $H 2$ (Figs. 6 and 7). The RMSs of $H 2$ of the unfiltered STCM and DTCM data are 30.9 $\mathrm{nT}$ and $32.0 \mathrm{nT}$, respectively. The correlation coefficients between $H 1$ and phase-shifted $Z$ of the unfiltered STCM and DTCM data are 0.27 and 0.92 , respectively. We extracted the anomalies of the scales corresponding to the 


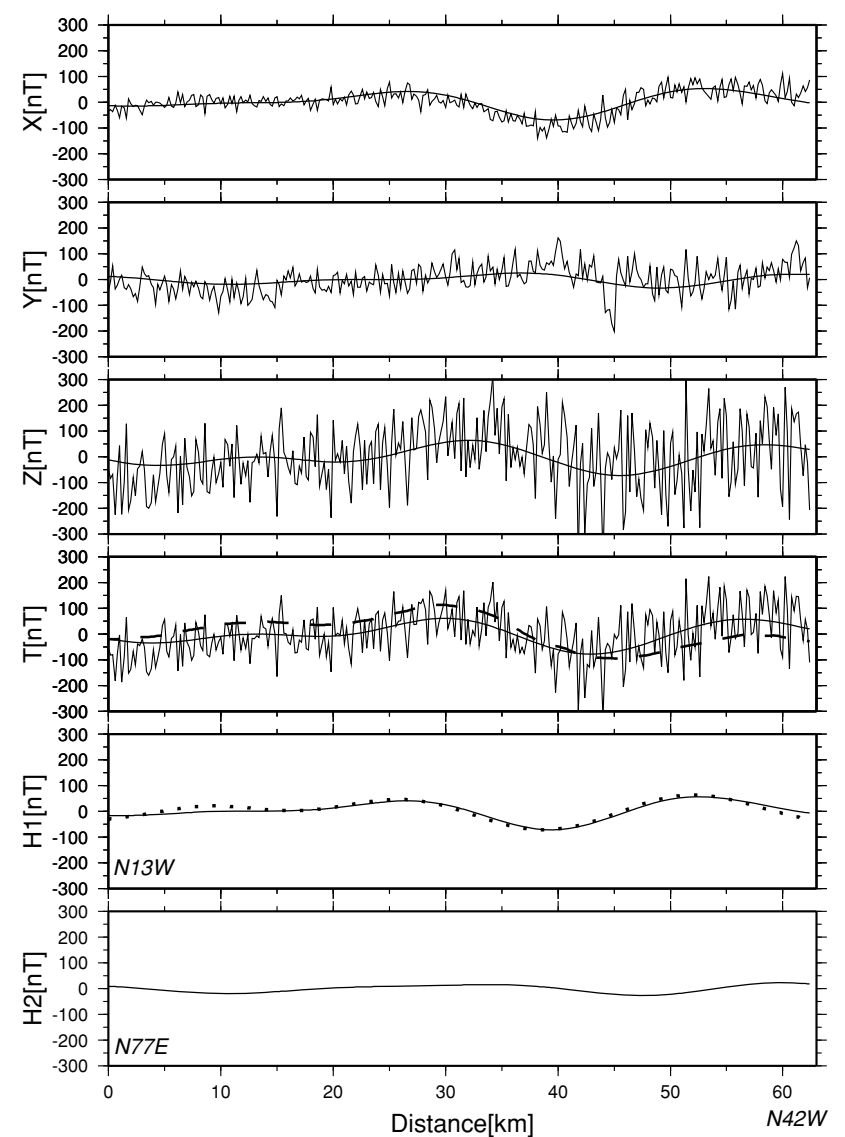

Fig. 4. Anomalies of the STCM profile in the Tsushima Basin. The azimuth of this profile is $\mathrm{N} 42^{\circ} \mathrm{W} . X, Y, Z$, and $T$ are northward, eastward, vertical downward, and total intensity of anomaly, respectively. $H 1$ and $H 2$ are horizontal components which minimize the RMS of $H 2$. The solid lines are band-pass filtered anomalies. The dashed line of $T$ is the total intensity of the anomaly measured by PPM on the sea-surface. The dotted line of $H 1$ is the anomaly calculated by shifting the phase of $Z$ by $\pi / 2$.

Fourier wavelength $18.64-26.37 \mathrm{~km}$ and more than $8.70 \mathrm{~km}$ from the STCM and DTCM data by the band-pass filtering. The filtered STCM and DTCM data show the azimuth $\mathrm{N} 47^{\circ} \mathrm{E}$ which minimizes the RMSs of $\mathrm{H} 2$ (Figs. 6 and 7). The RMSs of $H 2$ of the filtered STCM and DTCM data are $8.4 \mathrm{nT}$ and $25.1 \mathrm{nT}$, respectively. The correlation coefficients between $H 1$ and phase-shifted $Z$ of the filtered STCM and DTCM data are 0.89 and 0.96 , respectively. The PPM $T$ has a high correlation with the filtered STCM $T$ (Fig. 6).

These results show that magnetic anomalies due to the 2-D magnetic source are more dominant than those due to the other sources in both basins. However, the STCM data show the two-dimensionality only in a narrow range of wavelength compared to DTCM data, indicating that STCM data contain noises or magnetic fields produced by the other magnetic sources in a broad range of wavelength compared to DTCM data. We therefore adopted the azimuths of $\mathrm{H} 2$ determined from the filtered DTCM anomalies as the strikes of 2-D magnetic source in their areas. The strikes are $\mathrm{N} 82^{\circ} \mathrm{E}$ in the Tsushima Basin and $\mathrm{N} 47^{\circ} \mathrm{E}$ in the Japan Basin.

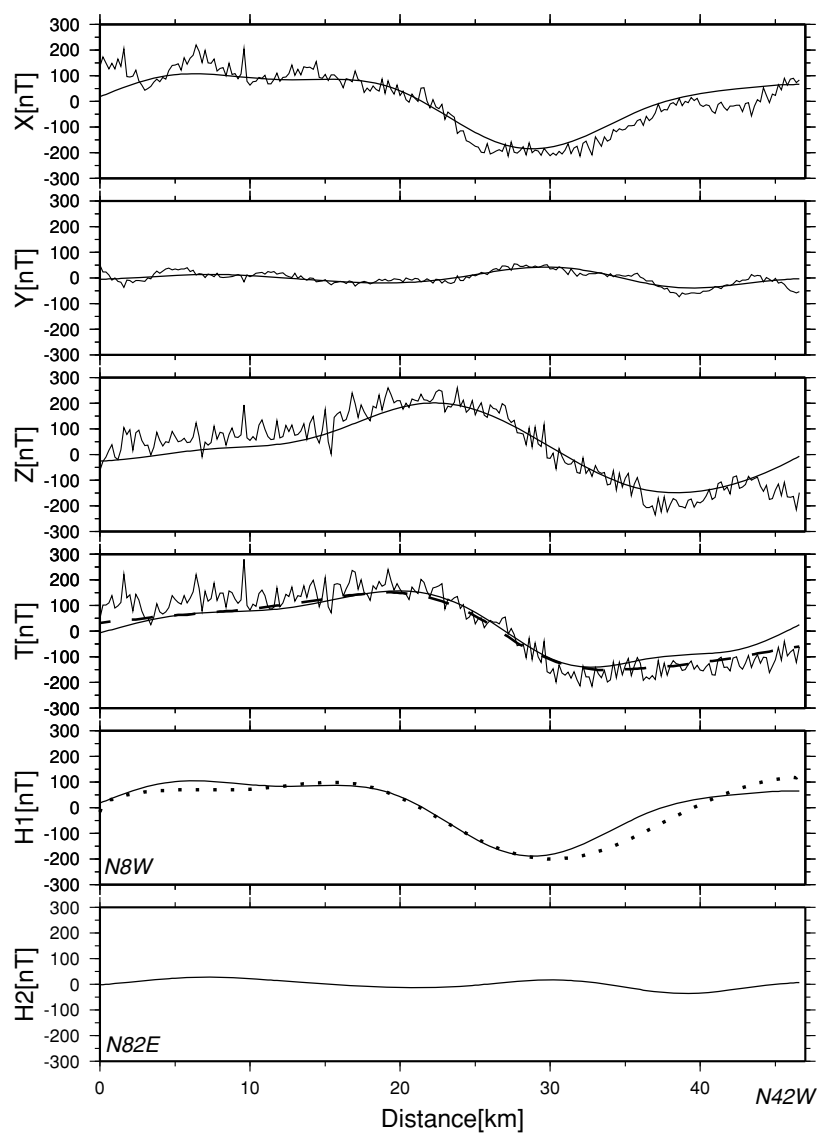

Fig. 5. Anomalies of DTCM profile in the Tsushima Basin. The azimuth of this profile is $\mathrm{N} 42^{\circ} \mathrm{W}$. See Fig. 4 for details.

\section{The Characteristics of Magnetic Structure}

It is possible to estimate the general features of the 2D magnetic structures in the Tsushima and Japan Basins because the DTCM anomalies in both basins show high two-dimensionality. For a potential field inversion, we need basic prior information of the source (the position and the shape). Previous studies proposed that Layer $2 \mathrm{~A}$, which is composed of extrusive basalts, is generally the main contributor to linear marine magnetic anomalies but that the deeper crust could be also the contributor (e.g., Harrison, 1987). At DSDP/ODP Hole 504B, which is drilled in the typical oceanic crust, NRM intensities of extrusive basalts and sheeted dike complex are on average $5.2 \mathrm{~A} / \mathrm{m}$, with a large standard deviation, and on average $1.6 \mathrm{~A} / \mathrm{m}$, with a small standard deviation, respectively (Pariso and Johnson, 1991). In the Japan Basin, the results of seismic studies suggested that the depth of Layer $2 \mathrm{~A}$ is about $5.5-6.0 \mathrm{~km}$ below the sea-surface and that of Layer $2 \mathrm{~B}$ is about 6.0 $7.0 \mathrm{~km}$ below the sea-surface (e.g., Hirata et al., 1992). In the Tsushima Basin, studies based on seismic reflection and refraction profiles suggested that the crust is oceanic, but Layer 2A does not exist and there are many volcanic sills and flows in the deeper part of sedimentary layer in the central part of the Tsushima Basin (Kim et al., 1998; Lee et al., 1999). The depth of Layer $2 \mathrm{~B}$ is about $6.0-7.0 \mathrm{~km}$ below the sea-surface.

To detect the position of the 2-D magnetic source, we used the amplitude of analytic signal $A S$ (equation 16, 


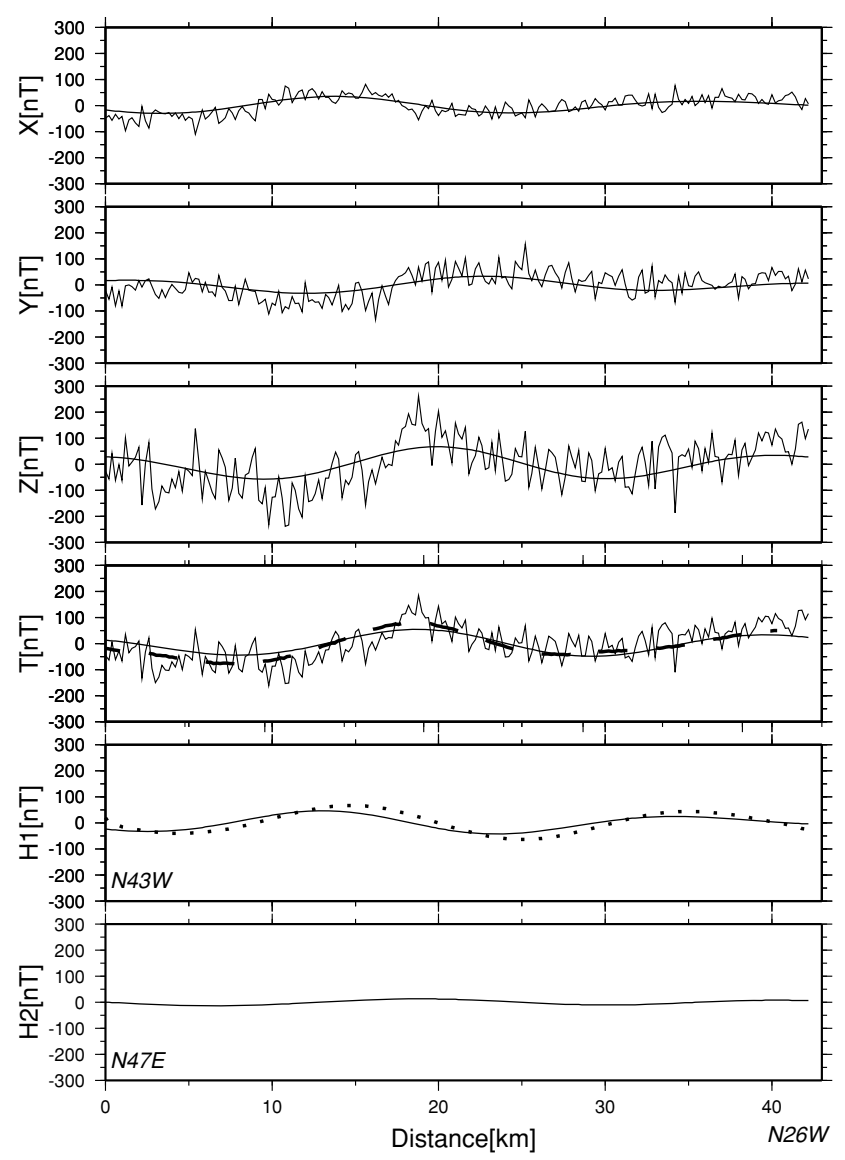

Fig. 6. Anomalies of STCM profile in the Japan Basin. The azimuth of this profile is $\mathrm{N} 26^{\circ} \mathrm{W}$. See Fig. 4 for details.

Nabighian, 1972) represented by the following equation.

$$
A S=\sqrt{\left(\frac{\partial H}{\partial p}\right)^{2}+\left(\frac{\partial Z}{\partial p}\right)^{2}}
$$

where $H$ and $Z$ are the horizontal and vertical downward components of anomaly, respectively, and $p$ is the horizontal coordinate. The advantage of this equation is that the calculation of $A S$ requires only numerical derivative. In the case that the magnetic anomalies are generated by a 2-D sheet with homogeneous magnetization, the peaks of $A S$ and the distance where the amplitude of $A S$ is a half of the peak-to-bottom amplitude show the horizontal end positions and the depth of the source, respectively (Nabighian, 1972, 1974). However, the conditions required for this method are too ideal for the representation of the real magnetic source to determine its position (particularly, its depth). We therefore determined the horizontal positions of magnetic sources from $A S$ and its depth from the seismic results by referring to the depth estimation of $A S$. Before the calculation of $A S$, we projected the track lines in the direction normal to the strikes of 2-D magnetic structures.

We next estimate the magnetization intensity of the magnetic model constructed from the above-mentioned method by least square fitting. Because the magnetic model is considered to be a 2-D structure, the estimated magnetization intensity reflects only the component in a plane normal to the 2-D structure. We assumed that the directions of mag-

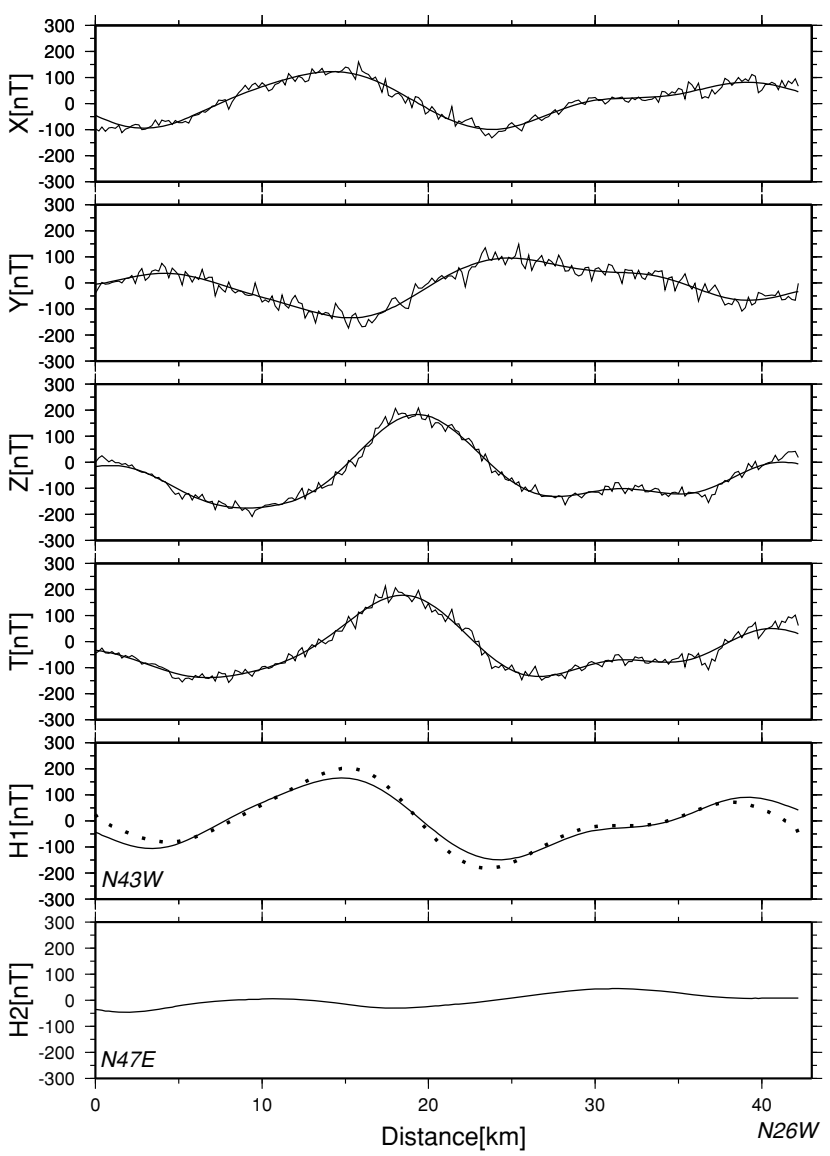

Fig. 7. Anomalies of DTCM profile in the Japan Basin. The azimuth of this profile is N26 W. See Fig. 4 for details.

netization (inclination: $I_{\mathrm{m}}$; declination: $D_{\mathrm{m}}$ ) are those of the geo-centric axial dipole at the sites $\left(\mathrm{GAD} ; I_{\mathrm{m}}=56.0\right.$ and $D_{\mathrm{m}}=0.0$ for the Tsushima Basin, and $I_{\mathrm{m}}=61.3$ and $D_{\mathrm{m}}=0.0$ for the Japan Basin), and that the directions of ambient field (inclination: $I_{\mathrm{r}}$, declination: $D_{\mathrm{r}}$ ) are those of IGRF at the sites $\left(I_{\mathrm{r}}=51.8\right.$ and $D_{\mathrm{r}}=-7.7$ for the Tsushima Basin, and $I_{\mathrm{r}}=57.3$ and $D_{\mathrm{r}}=-9.5$ for the Japan Basin). The effective inclinations (Gay, 1963) of magnetization and ambient field are calculated from these directions and the estimated strikes of 2-D magnetic structures. DTCM total intensity $T$ calculated directly from the observed three-component fields is adopted for the least square fitting. We assumed that $H 1$ and $Z$ also contain the magnetic fields due to the sources different from 2-D magnetic structures as well as $H 2$ and considered the projection of their components (RMS of $\mathrm{H2}$ ) to the direction of ambient field as the standard deviation of $T$. The calculation of magnetic model was done according to Blakely (1995).

In the Tsushima Basin, $A S$ has two large peaks and one small peak (Fig. 8(a)). The distance where the amplitude of the peak L2 decreases by a half is about $3.9 \mathrm{~km}$. This result shows that the depth of the magnetic source is about $4.7 \mathrm{~km}$ below the sea-surface (taking the depth of DTCM $(0.8 \mathrm{~km})$ into account), which is similar to the depth where $P$-wave velocity increases sharply (about $5.0 \mathrm{~km}$ below the sea-surface; Kim et al., 1998; Lee et al., 1999). Therefore, we assumed that the depth of the magnetic source is 5.0$6.0 \mathrm{~km}$ below the sea-surface. We first constructed a mag- 


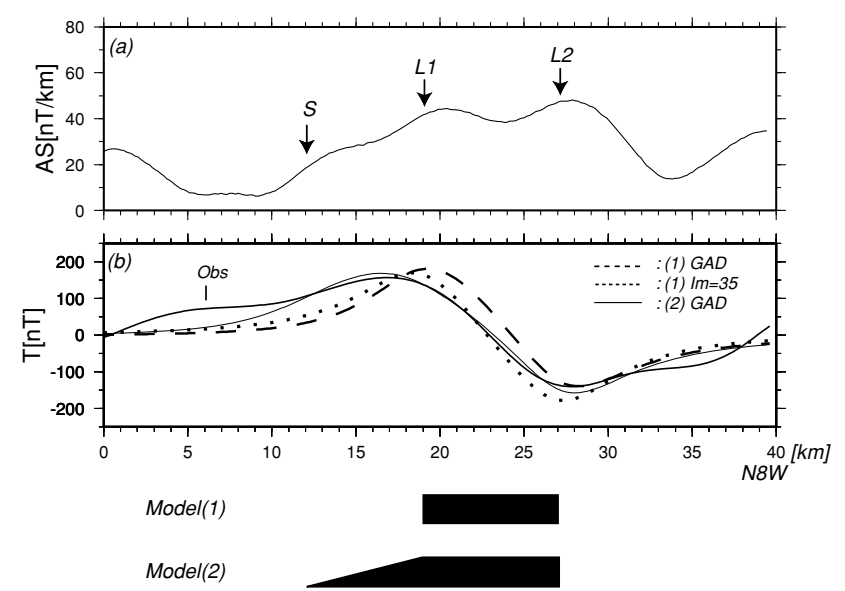

Fig. 8. Amplitude of analytic signal $(A S)$ and anomalies of DTCM profile for least square fitting with $A S$ in the Tsushima Basin. (a) $A S$. L and $\mathrm{S}$ represent large and small peaks of $A S$, respectively. (b) Total intensity of anomaly. Obs is the observed anomaly. The dashed line is the calculated anomaly with model (1) in which the direction of magnetization is that of the geo-centric axial dipole (GAD) at the site. The dotted line is the calculated anomaly with model (1) in which the direction of magnetization is $\left(I_{\mathrm{m}}, D_{\mathrm{m}}\right)=(35.0,0.0)$, which fits best the observed anomaly. The light line is the calculated anomaly with model (2) in which the direction of magnetization is that of GAD at the site.

netic model with one rectangular block representing two large peaks (L1 and L2; Fig. 8(a)). The calculated anomaly (dashed line; Fig. 8(b)) does not match with the observed anomaly and the RMS misfit is $48.4 \mathrm{nT}$. The estimated magnetization intensity is $5.0 \pm 0.1 \mathrm{~A} / \mathrm{m}$. We next estimated the magnetization intensity of the rectangular block by replacing the direction of magnetization with $I_{\mathrm{m}}=35.0$ and $D_{\mathrm{m}}=0.0$, which gives the minimum RMS misfit, keeping $D_{\mathrm{m}}$ constant. The calculated anomaly (dotted line; Fig. 8(b)) matches the observed anomaly better than the previous model, and the RMS misfit is $35.6 \mathrm{nT}$. The estimated magnetization intensity is $5.5 \pm 0.1 \mathrm{~A} / \mathrm{m}$. Whenever $D_{\mathrm{m}}$ is varied, the result is almost the same. We then constructed one trapezoid model representing two large peaks and one small peak (L1, L2 and S; Fig. 8(a)). The horizontal distance between peak $\mathrm{L} 1$ and peak $\mathrm{S}$ is $7 \mathrm{~km}$. The direction of magnetization is that of GAD at the site. The calculated anomaly (light line; Fig. 8(b)) matches well with the observed anomaly, and the RMS misfit improves significantly, that is $23.2 \mathrm{nT}$. The estimated magnetization intensity is $5.0 \pm 0.1 \mathrm{~A} / \mathrm{m}$.

$A S$ has four large peaks and one small peak in the Japan Basin (Fig. 9(a)). The distance where the amplitudes of the four large peaks (L1 to L4) decrease by a half is $3.7 \pm 0.5 \mathrm{~km}$. This result shows that the depth of the magnetic sources is $6.2 \pm 0.5 \mathrm{~km}$ below the sea-surface (taking the depth of DTCM $(2.5 \mathrm{~km})$ into account), which is almost identical with that of Layer $2 \mathrm{~A}(5.5-6.0 \mathrm{~km})$ and Layer 2B (6.0-7.0 km) determined by Hirata et al. (1992). We constructed a magnetic model with three rectangular blocks representing the four large peaks (L1 to L4). We assumed that the depth of the rectangular blocks is $5.5-6.0 \mathrm{~km}$ below the sea-surface. The calculated anomaly (dashed line; Fig. 9(b)) matches with the observed anomaly except for the short wavelength anomaly near the small peak S. The RMS
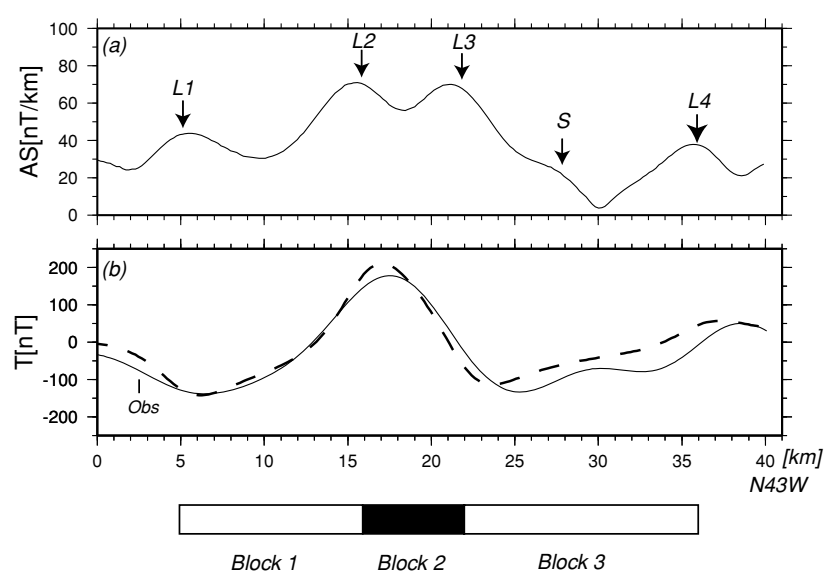

Fig. 9. Amplitude of analytic signal $(A S)$ and anomalies of DTCM profile for least square fitting with $A S$ in the Japan Basin. (a) $A S$. L and $\mathrm{S}$ represent large and small peaks of $A S$, respectively. (b) Total intensity of anomaly. Obs is the observed anomaly. The dashed line is the calculated anomaly with three blocks. The direction of magnetization is that of GAD at the site.

misfit is $32.1 \mathrm{nT}$. The magnetization intensities of block 1 , block 2 , and block 3 are $-5.1 \pm 0.3 \mathrm{~A} / \mathrm{m}, 4.6 \pm 0.3 \mathrm{~A} / \mathrm{m}$, and $-2.9 \pm 0.3 \mathrm{~A} / \mathrm{m}$, respectively.

\section{Discussion}

\subsection{Tsushima Basin}

As mentioned in the previous section, the estimated magnetizations of the three models show normal polarity and similar intensities (5.0-5.5 A/m), but the RMS misfits among their models differ significantly. In the case that the direction of magnetization is that of GAD at the site, the trapezoid model fits the observed anomaly better than the rectangular model. The rectangular model using the alternative inclination of magnetiztion improves the RMS misfit. However, this inclination requires that the magnetic source was formed at the paleolatitude $20^{\circ}$ or tilted by $21^{\circ}$ after the formation near the present position. The geological and geophysical evidence supporting these situations has not been found. Hence, the trapezoid model may be representive of the 2-D magnetic structure in this region (Fig. 10).

There is a gravity anomaly highly expanded to NE direction in the Tsushima Basin (e.g., Park et al., 2002), and it is interpreted as a fossil abandoned spreading axis (Park et al., 2006). The strike of the magnetic structure estimated in this study $\left(\mathrm{N} 82^{\circ} \mathrm{E}\right)$ is quite different, possibly indicating that the magnetic structure is due to the formation mechanism, which is not related to the NE spreading axis.

The studies based on the seismic methods suggested that the crust in the central part of the Tsushima Basin is of oceanic origin affected by a mantle plume (Kim et al., 1998) or that the incipient oceanic crust is thickened by uppermantle thermal perturbations evoked by rifting (Lee et al., 1999). Layer 2A disappeared by the thick sediment cover which seals the extrusive basalts and enhances hydrothermal circulation in abundant porosity (Kim et al., 1998). There are volcanic sills and flows in the lower part of the sedimentary layer (Lee et al., 1999). However, the estimated magnetization intensity of $5.0 \mathrm{~A} / \mathrm{m}$ is similar to that of typical extrusive basalt. Moreover, this value is appar- 


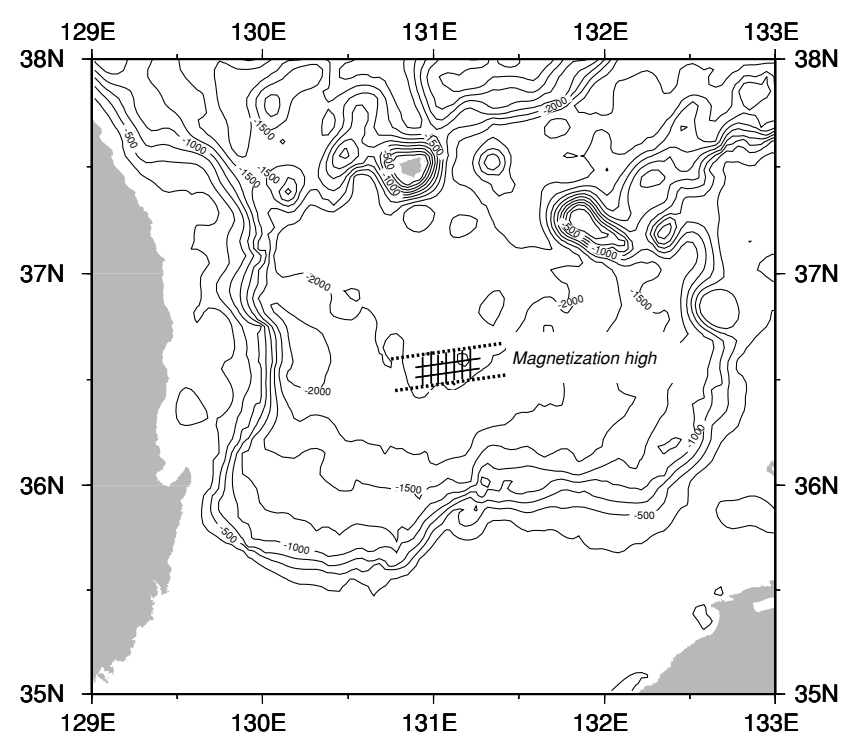

Fig. 10. Distribution of the magnetization high in the central part of the Tsushima Basin.

ently higher than the NRM $(1.5 \mathrm{~A} / \mathrm{m})$ of mafic rocks intercalated in sediments determined by magnetic measurements of ODP Hole 794D cores in the Yamato Basin (Fukuma et al., 1998). Another important characteristic of the magnetic structure is that the magnetization at the depth $5.0-6.0 \mathrm{~km}$ below the sea-surface exists partly. The thick sediment cover would not be responsible for this because the thickness of Layer 1 in the central part of the Tsushima Basin is almost constant. On the other hand, Hirata et al. (1989) suggested that the intrusions of a large amount of dikes at the end stage of seafloor spreading caused by the change of tectonics from tensional to compressional field altered Layer 2 to sill-sediment complexes in the south part of the Yamato Basin. The tectonic regime of the Tsushima Basin changed to back-arc closing from back-arc opening at the late Miocene (Chough and Barg, 1987; Yoon and Chough, 1995). However, the intrusions of a large amount of dikes may also be unsuitable for explaining the partial magnetization high because the scale of the mechanism is too large. Therefore, these magnetic characteristics may at least indicate that the entire sources of magnetic lineations in the Tsushima Basin did not alter to low magnetization after the formation.

\subsection{Japan Basin}

The estimated magnetization intensities of the magnetic model whose depth is $5.5-6.0 \mathrm{~km}$ below the sea-surface are $2.9-5.1 \mathrm{~A} / \mathrm{m}$. Their true values should be greater because the component of magnetization parallel to the strike of magnetic sources is not taken into account. Considering the source thickness and depth, the estimated magnetization intensities would indicate that of typical extrusive basalt. The small difference between the source depths determined by $A S$ and the seismic method may be not significant, taking the imperfection of two-dimensionality of the anomalies into account. Therefore, these results indicate that the observed anomalies in the Japan Basin are mainly generated by Layer $2 \mathrm{~A}$. The model based on four large peaks of $A S$, however, cannot explain the short wavelength compo-
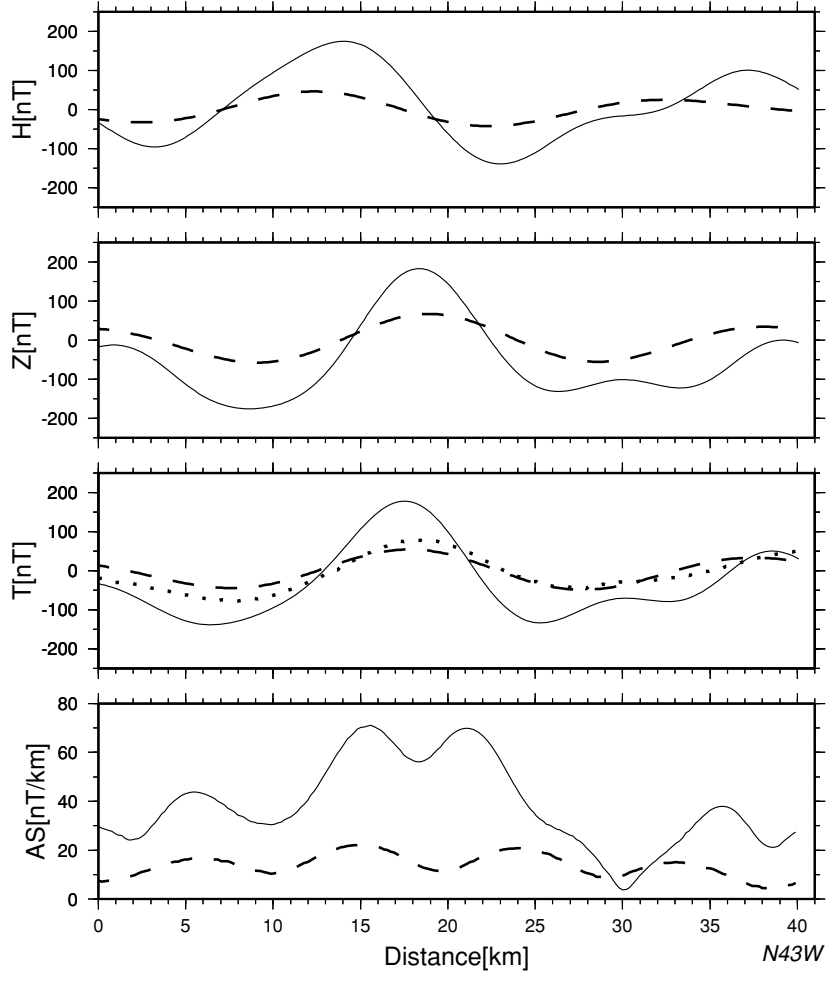

Fig. 11. Comparison of DTCM, STCM, and PPM profiles in the Japan Basin. $H, Z$, and $T$ are the horizontal $(H 1)$, vertical downward components and total intensity of anomaly, respectively. $A S$ is the amplitude of analytic signal. The solid lines are those of DTCM profile. The dashed lines are those of the STCM profile. The dotted line is $T$ by PPM on the sea-surface.

nent of the anomaly near the small peak of $A S$ (peak $\mathrm{S}$ in Fig. 9(a)). This short wavelength anomaly may be due to short polarity event whose boundary cannot be detected by $A S$ or paleointensity variation.

Figure 11 shows the filtered STCM and DTCM profiles in the Japan Basin. The anomalies measured by DTCM show a larger amplitude than those measured by STCM, and they contain short wavelength anomalies which are not present in STCM profile. This indicates that DTCM data work better than STCM data for the identification of shorter paleomagnetic events in the Japan Basin. In addition, the results of the band-pass filtering for the STCM and DTCM data show the same strike of magnetic lineations, but the positions of $A S$ peaks determined from STCM and DTCM data, which represent those of magnetic boundaries, are different. The cause would be that STCM data is composed only of the anomalies in a narrow range of wavelength compared to DTCM data because of noises in a broad range of wavelength. This indicates that DTCM data work better than STCM data for the determination of magnetic boundaries. A more adequate filter must be designed to conduct a detailed analysis with STCM data.

The estimated strike of magnetic lineations in this study $\left(\mathrm{N} 47^{\circ} \mathrm{E}\right)$ is similar to results obtained by the previous STCM observation (Seama and Isezaki, 1990). Comparing the observed anomalies measured by DTCM with the anomaly profiles in the South Atlantic, which are the basis of the Cenozoic geomagnetic polarity time scale (Cande and Kent, 1992, 1995), the waveform of the de-skewed 

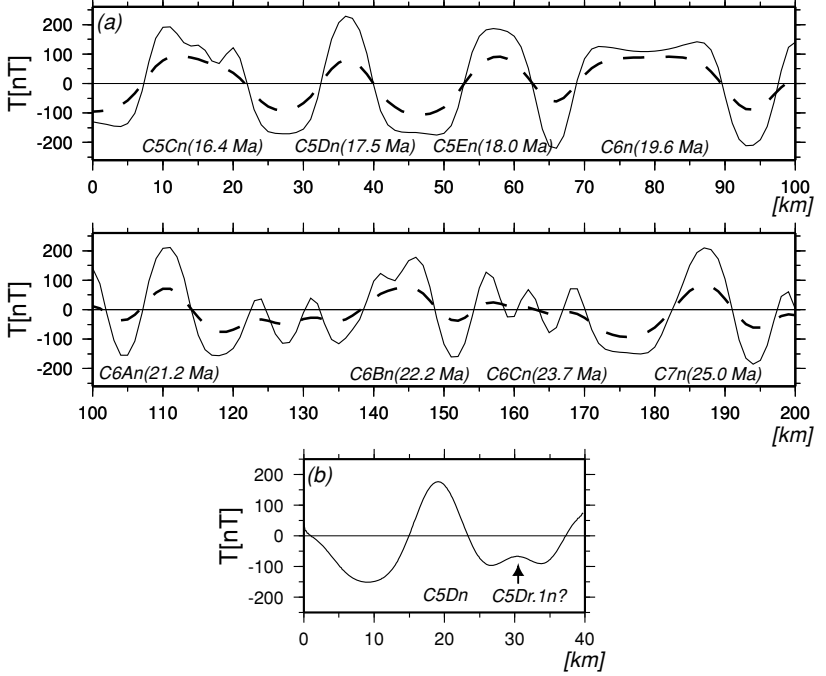

Fig. 12. Synthetic de-skewed profiles in the period from chron C5Cn (16.4 Ma) to chron C7n (25.0 Ma). (a) Synthetic de-skewed total intensity of anomaly. The depth of magnetic layer is $5.5-6.0 \mathrm{~km}$ below the sea-surface. The magnetization intensity is $5.0 \mathrm{~A} / \mathrm{m}$. The geomagnetic polarity reversal timescale refers to Cande and Kent (1995). The half-spreading rate is $2.0 \mathrm{~cm} / \mathrm{yr}$. The solid line is the synthetic profile whose depth is $2.5 \mathrm{~km}$ below the sea-surface. The dashed line is the synthetic profile on the sea-surface. (b) De-skewed total intensity of the observed anomaly measured by DTCM.

(Schouten and Cande, 1976) observed anomalies is similar to those of chrons $\mathrm{C} 5 \mathrm{Cr}$ (reverse polarity; 16.72617.277 Ma), C5Dn (normal polarity; 17.277-17.615 Ma), and C5Dr (reverse polarity; 17.615-18.281 Ma). In this case, the short wavelength anomaly near peak S may indicate a short normal polarity subchron C5Dr.1n which was identified by a paleomagnetic study (Channell et al., 2003). Based on this identification, the average half-spreading rate in this interval is about $2.0 \mathrm{~cm} / \mathrm{yr}$, which is slower than that determined by Isezaki (1986a). We next made the synthetic de-skewed profiles at the sea-surface and at the depth of $2.5 \mathrm{~km}$ below the sea-surface, which are almost the same as the observation profiles, by assuming that the depth of the magnetic layer is $5.5-6.0 \mathrm{~km}$ below the sea-surface, the magnetization intensity is $5.0 \mathrm{~A} / \mathrm{m}$, and the half-spreading rate is $2.0 \mathrm{~cm} / \mathrm{yr}$ (Fig. 12). The synthetic de-skewed profile of the sea-surface does not show any difference among the waveforms of the anomalies and the positions of magnetic boundaries compared to that of the depth $2.5 \mathrm{~km}$ below the sea-surface. Moreover, the variations of magnetization intensity, depth, and thickness of magnetic structures would make the precise identification of ages, magnetic boundaries, and strikes of magnetic lineation by sea-surface observation more difficult. However, the ages of the magnetic lineations and the half-spreading rate obtained in this study may be also uncertain because the profile is unfortunately too short. Deep-tow observations in more wide area are required to reveal the tectonic history of the Japan Basin.

\section{Conclusion}

We have shown that the vector geomagnetic field data acquired by DTCM is more effective than a single component field (e.g., total intensity) and three-component field measured by STCM to examine the characteristics of magnetic anomaly and crustal magnetic structure. Magnetic anomalies measured by DTCM in the northeastern part of the Japan Basin and the central part of the Tsushima Basin both show the characteristics of linear magnetic anomalies. The strikes of the magnetic structures are $\mathrm{N} 47^{\circ} \mathrm{E}$ in the former area and $\mathrm{N} 82^{\circ} \mathrm{E}$ in the latter area. We have also shown that the use of analytic signal calculated from vector anomalies enables precise determination of the position and the shape of magnetic sources. The observed anomalies in the Japan Basin are mainly generated by Layer 2A, and their ages may be chrons $\mathrm{C} 5 \mathrm{Cr}$ (16.726-17.277 Ma), C5Dn (17.277-17.615 Ma), C5Dr (17.615-18.281 Ma), and subchron C5Dr.1n. The estimated half-spreading rate is $2.0 \mathrm{~cm} / \mathrm{yr}$. The observed anomalies in the Tsushima Basin show that there is a partial high magnetization. This may indicate that the entire sources of magnetic lineations in the Tsushima Basin did not alter to a low magnetization by the effect of thick sediment cover and the intrusions of a large amount of dikes after the formation.

Acknowledgments. The experiment in the Tsushima Basin was conducted under the agreement of joint reaserch between KORDI and Chiba University. We thank H. Fujimoto of Tohoku University and Japan Aviation Electronic Industry, Ltd. for the care and loan of RLG. We also thank the captains, officers, crew, and scientific members of R/V Eardo and R/V Tansei-maru. We acknowledge T. Fujiwara, an anonymous reviewer, and Editor T. Yamazaki for critical comments and suggestions. The figures in this paper were made using GMT software (Wessel and Smith, 1998).

\section{References}

Blakely, R. J., Potential theory in gravity and magnetic applications, 441 pp, Cambridge University Press, Cambridge, 1995.

Blakely, R. J., A. Cox, and E. J. Iufer, Vector magnetic data for detecting short polarity intervals in marine magnetic profiles, J. Geophys. Res., 78, 6977-6983, 1973.

Cande, S. C. and D. V. Kent, A new geomagnetic polarity timescale for the Late Cretaceous and Cenozoic, J. Geophys. Res., 97, 13,917-13,951, 1992.

Cande, S. C. and D. V. Kent, Revised calibration of the geomagnetic polarity timescale for the Cretaceous and Cenozoic, J. Geophys. Res., 100, 6093-6095, 1995.

Channell, J. E. T., S. Galeotti, E. E. Martin, K. Billups, H. D. Scher, and J. S. Stoner, Eocene to Miocene magnetostratigraphy, biostratigraphy, and chemostratigraphy at ODP Site 1090 (sub-Antarctic South Atlantic), Geol. Soc. Am. Bull., 115, 607-623, 2003.

Cho, H. M., H. J. Kim, H. T. Jou, J. K. Hong, and C. E. Baag, Transition from rifted continental to oceanic crust at the southeastern Korea margin in the East Sea (Japan Sea), Geophys. Res. Lett., 31, L07606, doi:10.1029/2003GL019107, 2004.

Chough, S. K. and E. Barg, Tectonic history of Ulleung basin margin, East Sea (Sea of Japan), Geology, 15, 45-48, 1987.

Fukuma, K., H. Shinjoe, and Y. Hamano, Origin of the absence of magnetic lineations in the Yamato Basin of the Japan Sea: Magnetic properties of mafic rocks from Ocean Drilling Program Hole 794D, J. Geophys. Res., 103, 17,791-17,805, 1998.

Gay, S. P., Standard curves for interpretation of magnetic anomalies over long tabular bodies, Geophysics, 28, 161-200, 1963.

Harrison, C. G. A., Marine magnetic anomalies: The origin of the stripes, Annu. Rev. Earth Planet. Sci., 15, 505-543, 1987.

Hirata, N., H. Tokuyama, and T. W. Chung, An anomalously thick layering of the crust of the Yamato Basin, southeastern Sea of Japan: the final stage of back-arc spreading, Tectonophysics, 165, 303-314, 1989.

Hirata, N., B. Karp, T. Yamaguchi, T. Kanazawa, K. Suyehiro, J. Kasahara, H. Shinobara, M. Shinohara, and H. Kinoshita, Oceanic crust in the Japan Basin of the Japan Sea by the 1990 Japan-USSR Expedition, Geophys. Res. Lett., 19, 2027-2030, 1992.

International Association of Geomagnetism and Aeronomy (IAGA) Divi- 
son V, Working VMOD, The 10th-Generation International Geomagnetic Reference Field, Geophys. J. Int., 161, 561-565, 2005.

Isezaki, N., A magnetic anomaly map of the Japan Sea, J. Geomag. Geoelectr., 38, 403-410, 1986a.

Isezaki, N., A new shipboard three-component magnetometer, Geophysics, 51, 1992-1998, 1986b.

Isezaki, N. and Y. V. Shevaldin, Geomagnetic anomalies of the Japan Sea, Geology and Geophysics of the Japan Sea, in Japan-USSR Monograph Series 1, edited by N. Isezaki, I. I. Bersenev, K. Tamaki, B. Y. Karp, and E. P. Lelikov, pp. 41-47, Terrapub, 1996.

Kim, H. J., C. H. Park, J. K. Hong, H. T. Jou, T. W. Chung, V. Zhigulef, and G. I. Anosov, A seismic experiment in the Ulleung basin (Tsushima basin), Southwestern Japan sea (East sea of Korea), Geophys. Res. Lett., 21, 1975-1978, 1994.

Kim, H. J., S. J. Han, G. H. Lee, and S. Huh, Seismic study of the Ulleung Basin crust and its implication for the opening of the East Sea (Japan Sea), Mar. Geophys. Res., 20, 219-237, 1998.

Kim, H. J., H. T. Jou, H. M. Cho, H. Bijwaard, T. Sato, J. K. Hong, H. S. Yoo, and C. E. Baag, Crustal structure of the continental margin of Korea in the East Sea (Japan Sea) from deep seismic sounding data: evidence for rifting affected by hotter than normal mantle, Tectonophysics, 364, 25-42, 2003.

Kono, M., Magnetic anomalies in the Sea of Japan: A speculation on the tectonic history, J. Geomag. Geoelectr., 38, 411-426, 1986.

Korenaga, J., Comprehensive analysis of marine magnetic vector anomalies, J. Geophys. Res., 100, 365-378, 1995.

Kurashimo, E., M. Shinohara, K. Suyehiro, J. Kasahara, and N. Hirata, Seismic evidence for stretched continental crust in the Japan Sea, Geophys. Res. Lett., 23, 3067-3070, 1996.

Lee, G. H., H. J. Kim, M. C. Suh, and J. K. Hong, Crustal structure, volcanism, and opening mode of the Ulleung Basin, East Sea (Sea of Japan), Tectonophysics, 308, 503-525, 1999.

Nabighian, M. N., The analytic signal of two-dimensional magnetic bodies with polygonal cross-section; its properties and use for automated anomaly interpretation, Geophysics, 37, 507-512, 1972.

Nabighian, M. N., Additional comments on the analytic signal of twodimensional magnetic bodies with polygonal section, Geophysics, 39, 85-92, 1974.

Nishizawa, A. and A. Asada, Deep crustal structure off Akita, eastern margin of the Japan Sea, deduced from ocean bottom seismographic measurements, Tectonophysics, 306, 199-216, 1999.

Pariso, J. E. and H. P. Johnson, Alteration processes at Deep Sea Drilling Project/Ocean Drilling Program Hole 504B at the Costa Rica rift: Implications for magnetization of oceanic crust, J. Geophys. Res., 96, 11,703$11,722,1991$.

Park, C. H., Crustal structure and evolution of the Ulleung Basin in the East Sea of Korea (the Japan Sea) by deep penetrating seismic refraction, reflection, and potential field data, Ph.D. thesis, Chiba University, 245 pp, 1998.

Park, C. H., N. Isezaki, N. Seama, H. Shon, and J. W. Kim, Study on deep crustal structure of the Ulleung Basin, the East Sea (Japan Sea), from separating shallow components of gravity anomalies, J. Geol. Soc.
Korea, 38, 519-535, 2002.

Park, C. H., J. W. Kim, N. Isezaki, D. R. Roman, and R. R. B. von Frese, Crustal analysis of the Ulleung Basin in the East Sea (Japan Sea) from enhanced gravity mapping, Mar. Geophys. Res., 27, 253-266, 2006.

Parker, R. L. and M. S. O'Brien, Spectral analysis of vector magnetic field profiles, J. Geophys. Res., 102, 24,815-24,824, 1997.

Sato, Ta., N. Takahashi, S. Miura, G. Fujie, D. H. Kang, S. Kodaira, and Y. Kaneda, Last stage of the Japan Sea back-arc opening deduced from the seismic velocity structure using wide-angle data, Geochem. Geophys. Geosyst., 7, Q06004, doi:10.1029/2005GC001135, 2006a.

Sato, Ta., To. Sato, M. Shinohara, R. Hino, M. Nishino, and T. Kanazawa, P-wave velocity structure of the margin of the southeastern Tsushima Basin in the Japan Sea using ocean bottom seismometer and airguns, Tectonophysics, 412, 159-171, 2006b.

Schouten, H. and S. C. Cande, Paleomagnetic poles from marine magnetic anomalies, Geophys. J. R. Astron. Soc., 44, 567-575, 1976.

Seama, N. and N. Isezaki, Sea-floor magnetization in the eastern part of the Japan basin and its tectonic implications, Tectonophysics, 181, 285297, 1990.

Seama, N., Y. Nogi, and N. Isezaki, A new method for precise determination of the position and strike of magnetic boundaries using vector data of the geomagnetic anomaly field, Geophys. J. Int., 113, 155-164, 1993.

Shinohara, M., N. Hirata, H. Nambu, K. Suyehiro, T. Kanazawa, and H. Kinoshita, Detailed crustal structure of northern Yamato Basin, Proc. ODP, Sci. Repts., 127/128, Pt. 2, College Station, TX (Ocean Drilling Program), 1075-1106, 1992.

Tamaki, K. and K. Kobayashi, Geomagnetic anomaly lineation in the Japan Sea, Mar. Sci. Mon., 20, 705-710, 1988.

Tamaki, K., K. Pisciotto, and J. Allan et al., Background, objective, and principal results, ODP Leg 127, Japan Sea, Proc. ODP, Init. Repts., 127, College Station, TX (Ocean Drilling Program), 5-33, 1990.

Tamaki, K., K. Suyehiro, J. Allan, J. C. Ingle, and K. A. Pisciotto, Tectonic synthesis and implications of Japan Sea ODP drilling, Proc. ODP, Sci. Result, 127/128, Pt. 2, College Station, TX (Ocean Driling Program), 1333-1348, 1992.

Torrence, C. and G. P. Compo, A practical guide to wavelet analysis, Bull. Am. Meteor. Soc., 79, 61-78, 1998.

Wessel, P. and W. H. F. Smith, New, improved version of the Genetic Mapping Tools released, EOS Trans. Am. Geophys. Union, 79, 579, 1998.

Yamamoto, M., N. Seama, and N. Isezaki, Geomagnetic paleointensity over 1.2 Ma from deep-tow vector magnetic data across the East Pacific Rise, Earth Planets Space, 57, 465-470, 2005.

Yoon, S. H. and S. K. Chough, Regional strike slip in the eastern continental margin of Korea and its tectonic implications for the evolution of Ulleung Basin, East Sea (Sea of Japan), Geol. Soc. Am. Bull., 107, 83-97, 1995.

H. Kato (e-mail: hkato@graduate.chiba-u.jp), N. Isezaki, C. H. Park, C. H. Kim, and M. Nakanishi 